\title{
A theology of the infinite
}

David T. Williams

Faculty of Theology

University of Fort Hare

ALICE

\begin{abstract}
A theology of the infinite

The idea of the infinity of God has recently come under pressure due to the modern world-view, and due to the difficulty of proving the doctrine. However, the idea of the infinite, as qualitatively different from the merely very large, has properties which may be applied to some traditional difficulties in Christian theology, such as the ideas of the Trinity and the Incarnation, particularly in regard to the limitation and subordination of the Son. Predication of infinity to God may then make the doctrine of God more comprehensible and rational. At the same time, however, this has implications for the nature of God, particularly in his relation to the material and to time. Not to be overlooked is the value of the idea from a pastoral perspective.
\end{abstract}

\section{Introduction}

In traditional theologies regarding the nature of God is found a statement of the infinity of God. This will usually be associated with positive statements about him, such as the ideas of his omnipotence, omniscience and omnipresence. Indeed, the idea of God's infinity is sometimes simply seen as a negative statement of what can be referred to in positive ways. God has all power, he is almighty; therefore his power is infinite. There is nowhere that it is possible to go to escape from God; therefore his presence is infinite.

\section{The basis of an idea of infinity}

Until recently, the idea of God's infinity was accepted without real question. Where the existence of God was accepted, it was not questioned but that he is infinite (Bolzano, 1950:84; Rucker, 1982:9 quoting Cantor). It was a commonplace throughout the Middle Ages, due no doubt to the strong influence of Greek philosophy on the ideas of that period. Interestingly, Aristotle rejected the ascription of infinity to God on the basis that this would mean that God was unin- 


\section{A theology of the infinite}

telligible (Sontag, 1962: 24). However Aquinas, despite following Aristotle in many ways, rejected this, and held that God is in fact infinite (Sontag, 1962:44). In more recent times, however, with a re-examination of so much that had been accepted almost without question, the idea of God's infinity has also been doubted. In particular, the strong influence of evolutionary ideas in every branch of thought, notably of course in the theory of natural selection in the development of diverse biological species, has contributed to a suggestion that God, like everything else, is in a state of change (Gruenler, 1983: 11). Thus in distinction to the Greek and medieval ideas of a static fixed universe and a stable society, with the obvious changes in the world being superficial compared to the essential stability of the universe, came the idea that all is developing, including God himself. God is therefore not infinite, but developing in relation to a universe that is also developing. God is in 'process', and although he is greater than humanity, he is not absolutely so. Likewise, the ontological argument is meaningless; there is no such thing as absolute perfection. Some things are only better, bigger, stronger or whatever, than others. All is relative.

In the light of this suggestion, it is necessary to re-examine the basis on which God is stated as infinite.

\subsection{Philosophical basis}

This root of the idea of infinity has already been alluded to in the reference to Greek philosophy. Augustine, "who adopted the Platonic philosophy to the Christian religion" (Rucker, 1982:3), thus believed that God is infinite. God is apart from the world, and different from it. Being very conscious of the limitations of humanity, people very naturally deny such limitations to deity. Thus Berkhof (1958:52) writes, “... we remove from our idea of God all the imperfections seen in His creatures, as inconsistent with the idea of a Perfect Being, and ascribe to Him the opposite perfection". Although Berkhof (1958:53) rejects a philosophical basis for the knowledge of God as "... on human conclusions rather than on the self-revelation of God in His divine Word", he does assume the perfection of God. Then if perfection is predicated of God, it would seem to follow that God is infinite (Sontag, 1962: 68).

\subsection{Psychological basis}

Related to this category is the deep desire within the human personality for the existence of an infinite being, for such a being provides a basis for security. If God is not of infinite power, there may always be the feeling that the particular problem of the moment is actually too great for him. In the Athens of Paul's day (Acts 17:23), the erection of an altar to the 'unknown god' was to ensure that every area of life was adequately protected by deity. 
Of course, the desire for protection leads to the accusation that God is simply a reflection of human need, and even that he does not exist at all. Belief in a god is simply a result of a desire for someone able to meet human problems, as Feuerbach suggested. This is essentially Descartes' view; for him the appreciation of his finitude could only be explained in relation to the existence of the infinite (cf. Farrer, 1959:14). An interesting variation on this is to attempt to predicate infinite potential to human beings (as in the New Age movement), but then it becomes problematic to differentiate them from a possible God (cf. Bohler, 1991:39), who is then effectively 'infinitely infinite'.

\subsection{Biblical basis}

Several texts may be suggested which support the idea of the omnipresence of God, such as in the prayer of Solomon at the consecration of the Jerusalem Temple:

Behold, heaven and the highest heaven cannot contain thee; how much less this house which I have built. ( $1 \mathrm{Ki}$. 8:27 cf also Is. 66:1, Ac. 7:49.)

Similar to this is the claim of omniscience, such that God knows everything (Jer. 23: 24; cf. also Ps. 139:1f).

Such claims may indeed be valid, but unless the universe is looked upon as infinite, this is not in fact a claim to infinity, but rather to being everywhere, which is not at all the same thing.

Perhaps more relevant are texts such as Mark 14:36, "Father, all things are possible to you" or Genesis 18:14, "Is anything too hard for the Lord?" Again however, these do not actually demand omnipotence.

\subsection{Causal basis}

A similar objection can be made against the idea that creation demands infinite power, so that God must be infinite. This is true if the universe is infinite, giving rise to a problem felt by both Augustine and Aquinas, who believed it to be impossible for an infinite to create an infinite (Kennedy, 1991:46). However, the infinity of the actual universe is doubtful; in this case, whereas it is clear that creation requires a very large amount of power indeed, this is not the same as infinite power, but could, at least in theory, be calculated.

Further to this is the suggestion that the world may well not be created, but could be eternal, or perhaps that spontaneous creation could be a normal feature of the universe (Davies, 1983:26, 215). 


\section{The idea of the infinite}

To a greater or lesser degree, such thinking is based upon an idea of God as very large. Such size or ability or even perfection is beyond human comprehension, but really only because of the limited ability of the human mind to understand such ideas.

However, the term infinite does not simply mean a size greater than can be conceived of, but means, as is the literal rendering of the word, something without a limit. This does not mean that the limit is so far beyond human reckoning that it may be understood as limitless, but that there really are no limits at all (Bolzano, 1950:81 f.). Neither of course does the infinite simply mean something without an end. There are several non-infinites which have this property, such as the circumference of a circle (Bolzano, 1950:83) or perhaps more interestingly, of a Möbius strip (Maor, 1987:139).' Other things are bounded and yet infinite, such as the space between two parallel lines (Bolzano, 1950:83). This understanding of infinite is of a qualitative difference from that of the merely very large and so has unique properties, well known in mathematics. Maor (1987:16) refers to a "googol", ten to the power of hundred, and a "googolplex," ten to the power of a googol, numbers that are completely beyond comprehension, bigger even than the number of atoms in the universe. He then remarks, "Big as these numbers are, they have nothing to do with infinity. In fact infinity is as remote from a googol as from 1". Then he adds, significantly, "it follows that infinity is not a number at all, but a concept."

This means that the properties of the infinite will not be the same as those of the finite that we are used to. Our experience is only of the finite, "they never transcend to the infinite" (Maor, 1987:58). There is a qualitative difference

An example of this is described in Sondheimer and Rogerson (1981:149). They use the example of the infinite set of positive integers. Here every number can be paired with members of a set of even numbers; thus 1 is paired with 2,2 with 4,3 with 6 , and so on. As the series are both infinite, no numbers are left in either set. They contain the same number of elements. However, the set of all integers must contain odd numbers, so it should have double the number as in the set of just the even numbers. Thus the paradox, which only applies as both sets are infinite, is that a set with twice the number of elements has exactly the same number. Twice infinity equals infinity (Kline, 1954:396). In the words of Sondheimer and Rogerson (1981:149):

A continuous loop with a half twist. This then has only one side and one edge. 
An infinite set can be 'put into one-to-one correspondence' with a proper sub-set of itself. This is a general property of infinite sets which is not possessed by any finite set ... .

It is a property such as this which can only belong to the idea of infinity. ${ }^{2}$ It is not a property of the simply very large, even of things larger than can actually be conceived of.

\section{The existence of the infinite}

It is relatively easy to conceive of an infinite and to describe its properties. This does not, however, mean that such a thing actually exists. Particularly in mathematics it is quite in order to describe, and to work with concepts which do not in fact exist in the physical world. An example of this is space with more dimensions than the three that we experience. It must be noted, however, that mathematical concepts are developed in general because they have use; even if they do not have actual existence, they do have actual application.

An example of this, related to the idea of the infinite, occurs in the theory of the infinitesimal calculus. This theory depends on the idea of infinitesimally small quantities, which approach non-existence, or zero. Now, if one of these is divided by another, the answer is not zero (as when a zero is divided by a number) or infinity (as when a number is divided by zero), but in the limit, where each approaches zero, the answer is indeterninate. The theory of calculus has proved to be an indispensible tool in mathematics, with enormous application in engineering. It is a concept which can be used, but it does not in fact depend on the actual existence on any of its infinitesimals

Rucker (1982:9) has helpfully discussed the idea of infinity and divided the possibilities into three: a fully independent absolute other-worldly being, real occurrences in the physical world, and conceptions as in mathematics.

As regards the second, the possibilities are that physical quantities are infinite in extent, or that they are infinitely divisible. Although it would seem at first sight that space and time are infinite, this would seem to be unlikely. In the case of space, Einstein's understanding would lead to a finite but unbounded universe because of the essentially curved nature of space (Maor, 1987:220). He also stressed the limiting parameter of the speed of light in the known universe (Gruenler, 1983:75).

2 Incidentally, this answers the problem of God's ability to create an infinite universe, as an infinite can cncompass another infinite. This is not to say that the universe is infinite, but the idca of creation does not preclude the possibility. 
The concept of entropy ${ }^{3}$ indicates that time cannot be infinite, even if it can be very long. Eventually the interaction of matter results in a uniform chaos in which there is no meaningful change and therefore no time. The reality of unidirectional change in the world leads to the necessity of a real origin and real conclusion for this world, so a 'big bang' (Rucker, 1982:12) as origin, and either an indefinite expansion in total chaos or a 'big stop' when everything contracts again after expansion to a limit. In the second case there is a possibility of an infinite repetition of the expansion-contraction cycle. ${ }^{4}$ However, this universe is limited in time.

The infinite divisibility of space and time seems more practicable. It was in this sense only that Aristotle accepted the possibility of the infinite (Sontag, 1962:44). However, the atomic view of matter and the quantum understanding of energy would indicate the lack of infinite divisibility. Even if modern atomic plysics has succeeded in going beyond the atom, there is no indication of absolute divisibility. From another perspective, when two things become infinitesimally close, they actually become one. They are no longer different (Rucker, 1982:31, referring also to Hume's insights).

It would seem probable that any form of infinity is impossible in the real world. Rucker (1982:51) however concludes:

There are, however, no conclusive proofs that everything is finite, and the question of whether or not anything infinite exists remains as an open, almost empirical problem ... There are various sorts of physical infinites that could actually exist ... Each of these infinites is, in principle, avoidable; whether or not our Cosmos does actually avoid infinities remains to be seen.

However, whether or not infinites do exist, they can certainly be conceived of, and then their properties can be described. For this we are indebted particularly to George Cantor (1845-1918), who put the mathematics of the infinite on a sound footing and described several of the properties of the infinite (Maor,

3 All real events in the universe are essentially irreversible; it is impossible to restore the universe to exactly the same state as before. The second law of thermodynamics indicates that overall, any process results in a measure of order being lost, so of an increase in chaos; entropy quantifies this process, so is constantly increasing.

4 The concept of entropy does not demand the existence of a creator, although that is perhaps the simplest explanation. It is possible, in theory, to explain even the observed increase in entropy in terms of initial natural events which produce a low entropy system, or perhaps in terms of continual creation or destruction of entropy (Davies, 1983:212). 
1987:53f). Although Cantor believed that the existence of irrational numbers ${ }^{5}$ shows that the infinite actually exists, he admitted that it is largely a thought process, actual existence being irrelevant to the values of the concepts (Maor, $1987: 54,62)$.

Thus, although it is impossible to divide a real thing into an infinite number of parts, there is no objection to conceiving of such, and neither is there a fundamental reason why these infinitesimals could not be perceived. The Heisenberg uncertainty principle ${ }^{6}$ reflects on human inability (at least with current technology), or perhaps more exactly, on human finitude. Neither is an infinite distance or time fundamentally impossible; it is real physical infinites which are questioned. Aristotle, in Physics wrote, "the infinite has a potential existence ... there will not be an actual infinite" (Maor, 1987:54).

My concen is with the nature of God. Rucker (1982:51) writes, “... once one has an infinite Absolute, one inust also have many conceivable infinites as well". It is interesting that here, as also in the case of Bolzano (1950:101) and elsewhere, it is the acceptance of God as infinite which adds weight to the argument for the existence of other infinites. The existence of God, and his nature of infinity is, however, simply accepted dogmatically as a presupposition. It cannot be proved, simply because of its own nature?

If God is infinite, this immediately means that God is different from the world and from humanity (Sontag, 1962:48). He is distinct, and although He may relate to the world and to humanity, there must always be a qualitative difference; God must be beyond time and space (Gruenler, 1983:76). It is for this reason that Aquinas rejected the possibility of the infinite in the physical world. He accepted that God is infinite, and wanted to preserve a distinction between the world and God (Rucker, 1982:49).

9 It is well known that numbers can not all be expressed exactly. Naturally some are, such as the integers ( $1,2,3$ ctc.), but some are not, but are expressed in repeating decimals (such as $0,333 \ldots$... This latter case is not real indeterminability but is because we use a number system based on 10 . In other systems exactness is possible, so that $0,333 \ldots$ is exactly one third. Nevertheless other numbers are 'irrational', such as the square root of 2 , $\pi$ (the ratio of a circumference of a circle to its diameter), and $e$ (the base of natural logarithms), and cannot be expressed exactly in any number system. In our normal decimal system they are expressed only as infinite series.

6 It is impossible to determine everything about very small particles. The very act of attempting to do so changes their situation.

7 This aspect has implications for the Ontological Argument, which depends on the definition of God as perfect. This aspect requires a measure of comparability, whereas an infinity cannot be compared because it is indeterminate 


\section{Application to Christian theology}

Although it is impossible to prove that God is infinite by any of the ways that have been suggested, predicating infinity of God enables an explanation of a number of features in Christian theology which are otherwise difficult to understand. Its ability to do this would thus strongly indicate that God is infinite. The idea of Aristotle is turned around; whereas he denied infinity to God so that he could be known, God is actually better understood just because he is infinite. Whereas the concept of very large (such as a googol) is incomprehensible, an infinity is in fact better defined. It is fully compatible with rationality (Sontag, 1962:77). Whereas some of the statements of Christian theology have led to a rejection of Christianity because they are perceived as incomprehensible and even contradictory, their explanation in terms of the understanding of the nature of the infinite should lead to a greater acceptance of the faith (Kennedy, 1991:38).

This seeming paradox can be illustrated by the repeated tossing of coins. Each toss gives an unpredictable result, but overall, if a large number of tosses is performed, the result is effectively predictable. The use of an effective infinite enables accurate determination. This is of course the basis of the insurance industry, where although individual accidents are unpredictable, overall their occurrences can be predicted with great accuracy, enabling the risks and consequent premiums to be known.

This is not an absolute infinite, but a very large. The infinite is indeterminate, but the large is sufficiently close as to be usable, just as irrational numbers can only be given a practicable numerical value by approximation. ${ }^{8}$ The point is that a limitation is essential because the infinite is unmanageable. Similarly of course, if God is to relate to us, He must limit himself; a full expression cannot be appreciated by a limited humanity. Then it follows that the degree of self-limitation depends in the particular context. As infinite, God cannot be fully described in human terms; He is different, but it is possible to relate to him.

Real infinities can, however, be conceived of, described and used. Various quantities in mathematics, such as the irrational numbers (Maor, 1987:45), can be described in terms of infinite series, some of which can be summed. In these cases the determination is exact, but the definition involves infinity (Bolzano, 1950:93). It is impossible to write down the entire series, even if it can be conceptualized.

8 Thus the Biblical value of $\pi$ (1 Ki 7:23) given as three, is not an error; in fact all given values are approximate to some degrec, the only difference being the degrec of approximation. 
A further example of this is the Koch curve (Maor, 1987:78) ${ }^{9}$ which has the interesting property of an infinite perimeter, and in fact an infinite distance between any two points when following the perimeter, no matter how close they are. Yet the area enclosed by it is finite (Davies, 1983:15). In all these cases we have finitude and infinity in one figure. There is a combination of the incomprehensible with the comprehensible. Theologically, a parallel to this is that God is immanent, relating to the world and humanity, but at the same time differently transcendent. (See Maor, 1987:83 f. for some further examples combining the finite and infinite.)

In these cases, the use of the infinite renders understandable an otherwise incomprehensible. This would be true of God. We can say what He must be like, but can never exactly comprehend what we mean! By means of the infinite, his nature can be defined, but never exactly explained.

\subsection{God as Trinity}

The doginatic assertion that God is not an undifferentiated monad but is one God in three persons, however that is then understood, is distinctive to Christianity Obviously the basic idea comes from the realization of the divinity of Christ, based on his own assertions and observation of his life and deeds, and then subsequently on a realization of the divinity of the Holy Spirit. It is highly significant that this assertion took place in a religious culture that was emphatically monotheistic. The experience of Israel, particularly in exile, had led to a fear of anything approaching plurality in deity. This does not mean that simple monotheism is all that is to be found in the Old Testament; there are indications of plurality, such as the expression "let us make ..." of Genesis 1:26, but these are minor, and without a reading back of Trinitarianism, would not be seen as leading to it. Basically, the message of the Old Testament is that of monotheism. This contrasts strongly to a Greek culture which was very ready to ascribe deity due to the experience of anything surprising or miraculous, as Paul and Bamabas found at Lystra (Acts 11:12). These experiences were of course recorded in the Bible, and it was the attempts to reconcile the various assertions in the Bible which eventually led, by means of the Trinitarian controversies, especially that associated with the name of Arius, to the developed doctrine as understood today.

With the growth of Biblical criticism, the doctrine of the Trinity has come under attack as a dognatic invention which cannot really be deduced Biblically. If the Bible is viewed as containing much later material, especially as influenced by

9 This is generated by starting with an cquilateral triangle. At the centre of cach face is placed an equilateral triangle with each side a third of the original length. (This gives a 'star of David'.) The process is repeated on cach face of the new figure, and then again on the figure then generated, and so ad infinirum. 
Greek ideas, if it only contains a collection of disparate theologies, and especially if it is not to be seen as a valid revelation in its own right but a witness to religion, the doctrine of the Trinity rests on a very flimsy foundation. Attempts of such as Barth and Augustine to suggest a second root for the Trinity, the so-called Vestigia Trinitatis, are readily conceded to be weak.

The attack on the Trinity is of course strengthened by the difficulty of the doctrine, and by its irrelevance to practical Christian life and devotion. It can be suggested that Christianity can be a lot more credible, and so acceptable to modern humanity without it, and that Christianity would lose little.

It must, however, be observed that the doctrine not only explains the Biblical data, but does explain a number of other theological problems which do then occur in non-Trinitarian monotheism such as Islam and Judaism. For example, if God is love, how could this be possible before the creation of the world? Trinitarianism sees a solution in the inter-Trinitarian love between the Persons. Nevertheless, these are not great advantages compared to the difficulty of understanding how God can be at the same time singular and plural. Yet, if this can be explained satisfactorily, the Trinitarian solutions to other problems become meaningful. In this respect a perception of God's infinity is helpful.

If each person is infinite, the persons together are not three times the individual but exactly the same. Each person alone is no smaller than the group but is equal. Equally, they are really distinct, and not identical. ${ }^{10}$ This is not the same as Tertullian's suggestion of the unity that exists in a committee comprised of individuals, and is also more than that of Hodgson's social Trinity, which will both see the group as really more than the individuals. Here the very nature of the infinite means that the sum is exactly that of each individual person, and that each person alone is totally God, equal to the sum of the persons.

\subsection{God as incarnate}

A problem that immediately arises on ascription of deity to Jesus Christ, is how it is possible that God can be contained in a human frame. God is immense, and a human frame is so small. Thus, as already cited, when Solomon built the temple, in his dedicatory prayer he said that it was impossible for it to contain God, seeing that heaven itself could not contain him (1 Ki. 8:27). Jesus himself, in the later temple, referred to his own body as the temple (Jn. 2:21). The same thing is true; if a built temple could not adequately house God, then neither could a human body.

10 Infinite sets can be easily defined to be mutually exclusive, such as the sets of all even numbers, and of all odd numbers. They are absolutely equal, yet different. 
Therefore in references to the presence of God in the Old Testament temple, the language has a connotation of the "glory" of the Lord (e.g. Ez. 11:23), or of a symbol such as a cloud. And yet the implication is always of a real presence of God, such as when Ezekiel spoke to the Lord in that same temple, and certainly the implication of the New Testament is that Jesus did not simply represent God, but really was God.

Such is again possible if God is infinite. A very large being could not possibly be incarnated, yet a being without limits can be. There is no question of compressing, or taking a part to represent a whole, but the entire person of God was in Christ. He is limitless, and so the limits of a luman body are simply irrelevant. Although Aristotle could not reconcile infinity with form, later thought had no difficulty in so doing (Sontag, 1962:101). This is not a matter of reconciling two 'natures', one finite and one infinite, but of recognizing that a single being may be both.

Incidentally, the acceptance of humanity in incarnation is not the same as an inherent identification with the material. Pantheism, which identifies God with the material, is impossible if God is infinite, for the simple reason that the material is inherently limited, even if it is immense. ${ }^{11}$ There are suggestions that the universe is infinite, but this must be impossible due to the nature of the material. Rather modern suggestions are that there is some fonn of continuous creation, or that the universe is expanding from some primeval 'big bang'. Both of these imply a very definite limitation to the material.

Naturally a rejection of an identification of God with the material universe does not mean that God is not involved in the universe both as creator and as sustainer. He can be seen as in everything, even as its 'ground of being', but is infinitely greater than the sum of everything.

\subsection{God as limited}

Philippians 2:7 has occasioned an enormous amount of attention in relation to the incarnation, especially with the suggestion that in order to be incarnate, the Son of God emptied himself in order to be less than divine. Such could be seen as an explanation of the incarnation and of such features of the ignorance of Jesus as to the date of the second coming ( $\mathrm{Mk}$. 13:32). It is, however, obvious that there was a limitation in the incarnation; the infinite is incomprehensible. When confronted with the glory of God by the river Chebar, Ezekiel sat overwhelmed for

" God could incarnate as a universe, but not identify with it 
seven days (Ez. 3:15). When Joln saw the glory of the risen Christ on the island of Patmos, he "fell at his feet as though dead" (Rev. 1:17).

Yet the discussion on the kenotic theory of the incanation led to a reaffirmation of a full incarnation. The Son of God incarnate was not less in nature than as not incarnate. The incarnation was real. Nevertheless, there was a self-limitation, a self-restriction in order to relate to humanity.

Such a self-limitation should not in fact be surprising, as God limited himself in the creation, and especially in the creation of humanity. In order to give real free will, and in order to give real authority to the created, as the idea of the image of God (Gen. 1:26) should most likely be taken to mean, God limited himself, even if temporarily. When something is given to another, even if it is of an intangible nature such as power, the giver is naturally diminished by the amount given.

Although a self-limitation is not an inherent limitation of the power and authority of God, it may still be seen as unacceptable, both as involving change in God and as reflecting upon his absolute nature. However, if God is seen as infinite, with infinite power and authority, humanity can still be given real free will, power and authority, but God is in no way diminished by the gift. He still has infinite power; his authority over humanity is not at all lessened but is infinitely more than that of humanity. What is restricted is God's freedom, which is only absolute due to his infinity (Sontag, 1962:137); but to voluntarily restrict freedom is not an inherent limitation.

Traditional theologies have had difficulty with reconciling an essential unchangeability in God with Biblical references to his repentance, as well as to the facts of creation and incarnation. Whereas one solution is to see the essential idea of immutability not in a Platonic immobility where any change was rejected as it would involve a move away from perfection, but in consistency, reliability or faithfulness. However, insofar as an infinity can change and still remain infinite, God may be immutable just because he is infinite (Sontag, 1962:46).

To put it another way, limitation can be seen as consistent with infinity. To give a mathematical example, a series of even numbers by definition is limited; it does not include any odd numbers, yet it is still infinite (Bohler, 1991:38).

\subsection{The subordination of the Son}

A similar problem is that of the clear subordination of Jesus, focused in the statement of John 14:28 "the Father is greater than I". This is a key text for the argument of the ancient Arians, and in the modern world the Jehovalh's Witnesses, with their understanding of the Son as inherently less than God the Father, so implying a polytheism, a loss of the unity of God. 
It is possible to explain this text in terms of the fact that at the time of speaking, Jesus was self-limiting his nature. He was less than the Father, but only then, as the context may suggest, and was anticipating a restoration of his glory after his death. Such reasoning would, however, be unlikely in the case of John 10:29-30 where the greatness of the Father is again referred to, but with the immediate claim of Jesus - "I and the Father are one"

Altenatively, it can be explained in terns of relation, a view that as the Son, Jesus must be less than the source of his being, the Father, even if they are essentially equal. A human father and son are equal as regards humanity, but there is still a relational difference.

A more satisfactory way is to recognize that both Father and Son are infinite. Therefore of course they are absolutely equal, but also each is less than the other, even infinitely so. Any infinite is greater, even infinitely greater, than any other infinite. Thus the Son can say that the Father is greater than He, but at the same time He remains equal. As Rucker (1982:6) says, "the attributes 'equal', 'greater' and 'less', are not applicable to infinite, but only to finite quantities".

\subsection{The death of God}

One other peculiarity of the infinite is that infinity minus infinity is not zero as might be expected, but is indeterminate (Maor, 1987:8). This of course follows from the fact that adding anything to infinity, even another infinity, does not increase it. This can be suggested to have an application to the cross of Christ where God died. The absolute outrageousness of this has caused some in the past to reject it by suggesting that only the human nature in Christ died or that he only appeared to die. Nevertheless, the real death is essential if it is to be an adequate sacrifice for $\sin$.

The objections have been largely based in the Greek idea of the impassibility of God who cannot suffer or change in any way. This view naturally led to a dualism both in God and in humanity. More to the point is the idea that death diminished God, with implications for his ability to care for the world. However, as God is infinite, a real diminishing in his death does not in fact diminish him.

\subsection{The perception of God}

If God is limited, he can never, or very rarely, have a single experience of the whole of reality. The alternative is a fragmented God. Gruenler (1983:130) therefore has suggested that infinity is the only way of safeguarding the unity of 
God (cf. also Sontag, 1962:138). It can also provide a solution to the question of the perception and involvement of God in time. ${ }^{12}$

In any process of change, it is possible to conceive of an infinite number of states: there are an infinite number of instants in any period. This must be so to avoid the paradoxes which will otherwise occur. Kline (1954:403) refers to the problem of the flight of an arrow to illustrate this. At any instant its position can be identified, but at the next instant it is in a different position. Unless the next instant is infinitesimally close to the previous one, the arrow must be simultaneously at rest and in motion

Mathematically the paradox is that speed is distance divided by time. In an instantaneous change, the distance moved is zero, and as zero divided by anything is zero, the speed is zero. However, the time between instants is also zero, and anything divided by zero is infinite; thus the speed between two positions is infinite. The paradox is resolved in that zero divided by zero (or zero multiplied by infinity) is any quantity whatsoever. Thus the speed is neither infinite nor zero. Clearly this is only valid where the gap between two positions is infinitesimal, where there is an infinite number of states between the original and final positions.

Now where there are an infinite number of instants in a finite period, or of positions in a finite distance, it follows that it does not matter how big that finite period or distance is, there is still a one-to-one correspondence between the instants or positions in that period or distance with those of any other period or distance, no matter how big or small that period or distance is (Kline, 1954:402). Putting it crudely, no matter how big or small a period of time, or a length of space, it will contain the same number of instants or positions; that number is of course infinite.

What has this to do with the nature of God as infinite? The point is one of perception, for a finite mind or ability to perceive can obviously not observe every instant of time or position in space. Indeed it does not need to; Kline (1954:404) points out that the illusion of motion in a film is satisfied by the projection of a number of still pictures, or instants, on to a screen in succession. This number does not in fact need to be very high. Kline mentions a figure of sixteen per second, but any number of that order will be adequate, as long as it is not too low, when the illusion of motion is lost to be replaced by that of a series of still pictures, which is in fact the truth.

12 It is notoriously difficult to understand what time is. Perhaps the best is to see it as a description of the changes which take place compared to the changes in something else (Bolzano, 1950:131). Such a process of change can be seen as a succession of states following one another. 
Now this will be true of the human perception of anything at all. It will be of a rapidly changing sequence of impressions, a definitely finite, and quite a low number, in any period of time. Thus a human being does not perceive everything, but only what occurs in those instants. Anything else, such as when the person blinks, is just not observed; that perception is lost because the person is in time This is not true for God, who will observe everything. In any case, God is eternal and is effectively outside of time. ${ }^{13}$ To put it in another way, a human being observes by means of a finite number of impressions in any period, God by an infinite number. Unlike human perception, that of God is total; he is omniscient. ${ }^{14}$

There is a couple of results which follow from this observation. The first is, to me, a matter of speculation. It is frequently remarked by people who are getting older that the days seem shorter than in their youth and that they cannot get so much done. Time seems to be speeding up. Surely the problem would be that the number of perceptions is decreasing with age, there are less per unit of time. (This point is not relevant to this article, but is perhaps of further interest.)

The second, more importantly for theology, follows from the fact that God perceives an infinite number of instants in any period of real time. Because of the one to one correspondence of these instants with those of any other period, the length of time becomes irrelevant. In any period, God's perceptions are of an equal (infinite) number. Thus it is possible that with the Lord one day is as a thousand years, and a thousand years as one day (2 Pet. 3:8).

This is not simply a dogmatic assertion to explain the delay in the parousia, the second coming of Christ, the 'day of the Lord', but is firmly based on the nature of the infinite. (It may perhaps be suggested here that such a time difference between God's perception and that of the world can be explained by the relativity

13 To say that God is crerlasting is not adcquate as it predicates the idea of time onto God; thus implying that time is infinite. If time is a measure of change, it is only meaningful where the material changes, which is not the case when entropy maximizes in the chaos of the end of the universe, and is questionable before the initial event of the universe

To say that God is eternal is then to put him outside of time but that just as God is involved with the material, he is then able to interact with time. Not that He alters it, as that would limit the free will of people and affect the consequences of that free will, but it means that God's action has cternal effects.

An example of this is the efficacy of the atonement for the whole of time. Since it is an etemal act, it is effective for sins committed before the historical cvent, and also after the event. Of course as it is the infinite Christ who died, it is also effective for any amount of sin; there is no limitation.

14 This docs not demand determinism. God's perception is of all events, both actual and possible. 
theory in terms of the change in time experienced by a moving body (Gruenler, 1983:104), so that if God were moving at close to the speed of light, one day for him would be as a thousand years, but this would not explain the other half, one thousand years as a day, and certainly not at the same time.)

\section{The implication of infinity}

Any investigation of 'real' theology, the nature of God, must face the accusation of irrelevance to practical issues of Christian life and experience. Yet the application of religion must be based on an understanding of what deity is like. While theology is rooted in experience of what God has said and done, at the same time an appreciation of theology clarifies and enables experience. Here a realization of God's infinity has several consequences.

Very obviously a God of infinite power is more trustworthy than one of limited power, even if that power is large beyond actual comprehension.

Less obviously, but a point repeatedly stressed by Gruenler $(1983: 16)$ is that a non-infinite God cannot have a full, simultaneous perception of the whole of reality, especially due to the inherent limitation of the speed of light. Such a God cannot know everything at once, and so cannot respond to need.

While process theology is reacting against the 'immobility' of classical theism (Gruenler, 1983:14) by stressing the involvement of God in the world, such a God cannot be totally involved. In ordinary life, the greater an official, the harder it is to gain access. Such a person is too important to be concerned with every individual. Yet the glory of God's infinity is that he is so great that he can be concerned with everything. Technically this does not need infinity, but taken in conjunction with the previous point it does.

Perhaps the most significant implication of God's infinity concerns the relationship of believers to God. If deity is by nature infinite, then it is impossible for a limited human being to become divine, whether in the sense of the primeval temptation (Gen. 3:5) or in the modern versions as expressed in prosperity teaching or the New Age movement. While the infinite may accept limitation, the finite cannot become infinite. This stands in contrast to the Christian teaching of the adoption of believers as children of God (Rom. 8:15, Gal. 4:5). A Christian is not divinized, but benefits by a relationship to God. 'In Christ' is not absorption, but relation. It must be pointed out here that a view of God as personal, that is being able to relate, by no means reflects on his infinity, but actually the contrary.

In addition, human life can in no way be eternal by nature, as humanity is finite. Only God is inherently eternal (1 Tim. 6:16). Thus the only way of receiving etemal life is by relation to God, through adoption. 
Seeing God as infinite and so unique also stands in contrast to the common human attitudes of treating resources as if they were infinite. Human beings also tend to feel that they are naturally immortal. At the same time, of course, there is a resistance to admitting dependence on God; rather than accepting life as a gift from a gracious God, there is usually the attempt to seek to earn it. An appreciation of the infinite distance between humanity and God would go far to overcome these temptations.

\section{Conclusion}

Several years ago, J.B. Philipps, one of the pioneers in putting the Bible into simple language and so at least partly responsible for the glut of modern translations, wrote a little book entitled Your God is too small, in which he bemoaned the fact of the poverty of much that passes for religion, attributing it in part to a poor view of God. Certainly this continues to be true, exacerbated by increasing technical ability which encourages a belief in human solutions. This would be particularly true of South Africa which is increasingly inward looking due to the enormity of its problems.

And yet the continued inability of humanity to solve its problems, whether technical or political, should give rise to a new appreciation of human finitude, with then at the same time a longing for the infinite (Sinkler, 1989:79). A feeling of humility should lead to a desire for God's solutions.

Could it be that an investigation of the infinite does not lead only to the solution to problems in theology, but be the key to human problems as well?

\section{Bibliography}

BERKHOF, L. 1958. Systematic Theology. Edinburgh : Banner of Truth

BOHLER, C.S. 1991. Varieties of Religious Infinities. Christian Century, 108:38-39.

BOLZANO, B. 1950. Paradoxes of the Infinite. London : Routledge and Kegan Paul.

DAVIES, P. 1983. God and the New Physics. London : Penguin.

FARRER, A. 1959. Finite and Infinite: a Philosophical Essay. 2nd ed. Westminster : Dacre.

GRUENLER, R.G. 1983. The Inexhaustible God: Biblical Faith and the Challenge of Process Theism. Grand Rapids : Baker

HORN, J.N. 1989. From Rags to Riches: an Analysis of the Faith Movement and Its Relation to the Classical Pentecostal Movement. Pretoria : UNISA.

KENNEDY, R. 1991. The Application of Mathematics to Christian Apologetics in Pascal's Pensees and Arnauld's the Port-Royal Logic. Ficles et Historia, 23:37-52.

KLINE, M. 1954. Mathematics in Western Culture. London: George Allen and Unwin.

MAOR, E. 1987. To Infinity and Beyond: a Cultural History of the Infinite. Boston, Basel, Stuttgart : Birkhauser

RUCKER, R. 1982. Infinity and the Mind: the Science and Philosophy of the Infinite. Boston Basel, Stuttgart : Birkhauser. 
SINKLER, G. 1989. Causal Principles, Degrees of Reality and Priority of the Infinite. Canadian Journal of Philosophy, 19 (1):61-81.

SONDHEIMER, E \& ROGERSON, A. 1981. Numbers and Infinity: a Historical Account of Mathematical Concepts. Cambridge : Cambridge University Press.

SONTAG, F. 1962. Divine Perfection: Possible Ideas of God. London: SCM 